\title{
Targeting Mitochondria by Olesoxime or Complement 1q Binding Protein as a Novel Management for Autism: A Hypothesis
}

\author{
A. Ghanizadeh \\ Research Center for Psychiatry and Behavioral Sciences, Department of Psychiatry, Shiraz University of \\ Medical Sciences, Shiraz, Iran
}

\section{Key Words}

Autism $\cdot$ Complement $\cdot$ Mitochondria $\cdot$ Permeability

transition pore $\cdot$ Treatment

\begin{abstract}
Excitotoxicity, oxidative stress, and mitochondrial dysfunction are associated with autism. Considering the preventive role of complement $1 q$ binding protein or olesoxime for the opening of mitochondrial permeability transition pore mediated by oxidative stress, it is hypothesized that complement $1 q$ binding protein or olesoxime may improve some symptoms of autism.

Copyright $\odot 2011$ S. Karger AG, Basel
\end{abstract}

The disturbance of antioxidant mechanisms and/or overproduction of free radicals may result in oxidative stress. It is largely recognized that oxidative stress is enhanced in autism [Mostafa et al., 2010; Palmieri and Persico, 2010]. For example, nitric oxide (NO) production is enhanced [Sweeten et al., 2004]. In addition, the activity of antioxidant systems such as superoxide dismutase enzyme [Meguid et al., 2010] and glutathione reserve capacity is lower in autism than in control groups [James et al.,

\section{KARGER}

Fax +4161306 1234

E-Mail karger@karger.ch

www.karger.com (c) 2011 S. Karger AG, Basel

1661-8769/11/0021-0050\$38.00/0

Accessible online at:

www.karger.com/msy
2009]. In fact, there is a vicious cycle that the impairment of mitochondrial function causes a greater extent of oxidative stress [Palmieri and Persico, 2010].

NO induces oxidative stress and mitochondria are a target for NO (fig. 1). Toxicity with NO slows down the respiratory chain [Clementi et al., 1998] leading to cellular ATP depletion [Brorson et al., 1999]. The inhibition of respiration contributes to disruption of the mitochondrial inner transmembrane potential [Hortelano et al., 1997] leading to the activation of mitochondrial permeability transition pore (mPTP) and NO-induced apoptosis [Hortelano et al., 1997]. Furthermore, it is suggested that antioxidant supplements plus polyunsaturated fatty acids improve autism [Meguid et al., 2010]. Moreover, mitochondrial energy metabolism is impaired and ATP levels are decreased in autism [Pastural et al., 2009; Palmieri and Persico, 2010]. Autism in itself is not a homogeneous disorder but a symptom occurring in many disorders with variable causes. Only in a small percentage of patients a mitochondrial abnormality has been reported [Palmieri and Persico, 2010]. Moreover, equilibrium in reactive oxygen species in physiological conditions is required. At present, there is not any curative approach for autism. Furthermore, there are just a few Food and Drug Administration-approved medications that are available 


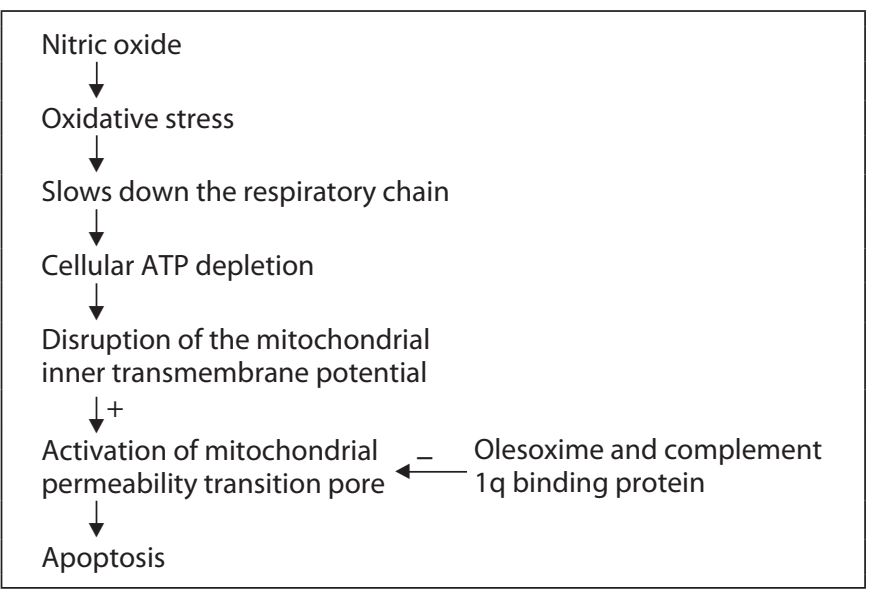

Fig. 1. The suggested association of oxidative stress and mitochondrial functioning in autism.

for treatment of autism. Therefore, there is an urgent need to find new solutions for autism treatment.

On the other hand, glutamate neurotoxicity [Harada et al., 2010] and excitotoxicity inflammation [Chauhan and Chauhan, 2006] are reported in autism. Moreover, glutamate synthesis inhibition decreases the neurotoxic activity in autism [Maezawa and Jin, 2010]. Meanwhile, the activation of the NMDA receptor may increase the NO level [Horn et al., 2002]. Cell death due to NMDA receptor agonists is reduced by blockade of $\mathrm{NO}$ synthesis [Kollegger et al., 1993]. Neuroinflammation, excitotoxicity, and oxidative stress are suggested as possible targets for treatment of autism [Ghanizadeh, 2010a, b, 2011a-c).
The MPTP is probably involved in neuronal injury due to excitotoxicity [Schinder et al., 1996]. Moreover, NO causes the release of calcium from mitochondria and induces intracellular calcium release by $\mathrm{MPTP}$ opening [Horn et al., 2002]. This leads to excitotoxicity.

Olesoxime is from the family of cholesterol-oximes that binds to some specific outer mitochondrial membrane proteins and prevents permeability transition pore opening mediated by oxidative stress [Bordet et al., 2010]. The neuroprotective effect of olesoxime is based on targeting mitochondria. The orally active compound of olesoxime is tolerated well. Complement 1q binding protein also prevents the $\mathrm{mPTP}$ opening through binding to $\mathrm{cy}$ clophilin D [McGee and Baines, 2010]. These phenomena will protect cells against oxidative stress.

In conclusion, the production of $\mathrm{NO}$ is increased [Sweeten et al., 2004] and oxidative stress is enhanced in autism [Mostafa et al., 2010; Palmieri and Persico, 2010]. Moreover, NO increases mPTP opening [Horn et al., 2002] and mitochondrial functioning is impaired in autism [Palmieri and Persico, 2010]. In addition, complement 1q binding protein [McGee and Baines, 2010] and olesoxime prevent permeability transition pore opening mediated by oxidative stress [Bordet et al., 2010]. Therefore, it is hypothesized that complement 1q binding protein or olesoxime may improve the condition of some patients with autism. So, it is worthwhile conducting the translational appropriate animal model studies to assess mitochondrial functioning [Patterson, 2011] that may open up novel possibilities for autism management.

\section{References}

Bordet T, Berna P, Abitbol J-L, Pruss RM: Olesoxime (TRO19622): A novel mitochondrialtargeted neuroprotective compound. Pharmaceuticals 3:345-368 (2010).

Brorson JR, Schumacker PT, Zhang H: Nitric oxide acutely inhibits neuronal energy production. The Committees on Neurobiology and Cell Physiology. J Neurosci 19:147-158 (1999).

-Chauhan A, Chauhan V: Oxidative stress in autism. Pathophysiology 13:171-181 (2006).

-Clementi E, Brown GC, Feelisch M, Moncada S: Persistent inhibition of cell respiration by nitric oxide: crucial role of S-nitrosylation of mitochondrial complex I and protective action of glutathione. Proc Natl Acad Sci USA 95:7631-7636 (1998).
Ghanizadeh A: Methionine sulfoximine may improve inflammation in autism, a novel hypothesized treatment for autism. Arch Med Res 4:651-652 (2010a).

Ghanizadeh A: Targeting neurotensin as a potential novel approach for the treatment of autism. J Neuroinflammation 7:58 (2010b).

Ghanizadeh A: Nuclear factor kappa B may increase insight into the management of neuroinflammation and excitotoxicity in autism. Expert Opin Ther Targets 15:781-783 (2011a).

Ghanizadeh A: Oxidative stress may mediate association of stereotypy and immunity in autism, a novel explanation with clinical and research implications. J Neuroimmunol 232:

194-195 (2011b).

Ghanizadeh A: Targeting of glycine site on NMDA receptor as a possible new strategy for autism treatment. Neurochem Res 36: 922-923 (2011c)

Harada M, Taki MM, Nose A, Kubo H, Mori K, et al: Non-invasive evaluation of the GABAergic/glutamatergic system in autistic patients observed by MEGA-editing proton MR spectroscopy using a clinical 3 tesla instrument. J Autism Dev Disord 41:447-454 (2010).

-Horn TF, Wolf G, Duffy S, Weiss S, Keilhoff G, MacVicar BA: Nitric oxide promotes intracellular calcium release from mitochondria in striatal neurons. FASEB J 16:1611-1622 (2002). 
Hortelano S, Dallaporta B, Zamzami N, Hirsch $\mathrm{T}$, Susin SA, et al: Nitric oxide induces apoptosis via triggering mitochondrial permeability transition. FEBS Lett 410:373-377 (1997).

James SJ, Rose S, Melnyk S, Jernigan S, Blossom $S$, et al: Cellular and mitochondrial glutathione redox imbalance in lymphoblastoid cells derived from children with autism. FASEB J 23:2374-2383 (2009).

Kollegger H, McBean GJ, Tipton KF: Reduction of striatal N-methyl-D-aspartate toxicity by inhibition of nitric oxide synthase. Biochem Pharmacol 45:260-264 (1993).

-Maezawa I, Jin LW: Rett syndrome microglia damage dendrites and synapses by the elevated release of glutamate. J Neurosci 30: 5346-5356 (2010).
McGee AM, Baines CP: Complement 1q binding protein inhibits the mitochondrial permeability transition pore and protects against oxidative stress-induced death. Biochem J 433:119-125 (2010).

Meguid NA, Dardir AA, Abdel-Raouf ER, Hashish A: Evaluation of oxidative stress in autism: defective antioxidant enzymes and increased lipid peroxidation. Biol Trace Elem Res (2010). Epub ahead of print.

Mostafa GA, El-Hadidi ES, Hewedi DH, Abdou MM: Oxidative stress in Egyptian children with autism: relation to autoimmunity. J Neuroimmunol 219:114-118 (2010).

Palmieri L, Persico AM: Mitochondrial dysfunction in autism spectrum disorders: Cause or effect? Biochim Biophys Acta 1797:11301137 (2010).
- Pastural E, Ritchie S, Lu Y, Jin W, Kavianpour A, et al: Novel plasma phospholipid biomarkers of autism: mitochondrial dysfunction as a putative causative mechanism. Prostaglandins Leukot Essent Fatty Acids 81:253-264 (2009).

Patterson PH: Modeling autistic features in animals. Pediatr Res 69(5 Pt 2):34R-40R (2011).

Schinder AF, Olson EC, Spitzer NC, Montal M: Mitochondrial dysfunction is a primary event in glutamate neurotoxicity. J Neurosci 16:6125-6133 (1996).

-Sweeten TL, Posey DJ, Shankar S, McDougle CJ: High nitric oxide production in autistic disorder: a possible role for interferon-gamma. Biol Psychiatry 55:434-437 (2004). 